\title{
A RE-EXISTÊNCIA COMEÇA NO DIÁLOGO - SOBRE EDUCAÇÃO POPULAR E FORMAS OUTRAS DE AVALIAÇÃO
}

Noelia Rodrigues Pereira Rego ${ }^{(*)}$

\section{CAMINHOS E DESCAMINHOS DA EDUCAÇÃO POPULAR}

A Educação Popular é uma forma de educação, se assim podemos chamá-la, ou mesmo uma categoria ou linguagem pedagógica, que difere em grande medida dos processos educativos a que estamos acostumados. Isto porque ela tem um significado e um significante bem peculiar: ela nasce no bojo dos movimentos sociais, sobretudo em Latino-américa. Desta feita, se torna um instrumento fundamental para o fortalecimento de epistemes outras, que estão ancoradas no cotidiano, nas vivências e experiências, nas crenças, nas rezas, nas peculiaridades de cada povo, de cada grupo que habita estas terras. É assim que a EP é construída no e com o coletivo, por meio de suas práticas cotidianas e de seus saberes singulares.

Dentro de suas trajetórias de existência e RE-existência, a Educação Popular propõe uma insurgência radical com as concepções pedagógicas enrijecidas, tradicionais e carregadas de paradigmas meritocráticos e competitivos, contrapondo-se, por exemplo, às chamadas "habilidades e competências pretendidas", que constam de documentos oficiais como a LDB $^{1}$, por exemplo. É no interior deste prisma que se dá o antagonismo entre EP e educação tradicional, esta que tem no campo do formal sua consolidação. Nos campos informais e não-formais estão forjadas a EP com suas congruências heurísticas do fazer junto, engajado, aguerrido, altero. Nesta forma outra de educação, não há "donos do saber", pois nela todx ${ }^{2}$ s sabem e todxs são aprendentes, ao mesmo tempo.

\footnotetext{
${ }^{(*)}$ Educadora popular, doutora em Educação pelo Programa de Pós-graduação em Educação - Universidade Federal do Estado do Rio de Janeiro, membro do Coletivo de Educação Popular e Libertária (CEPL). E-mail: noeliarpr @ gmail.com. ORCID: <https://orcid.org/0000-0001-5248-5941>.

${ }^{1}$ Lei de Diretrizes e Bases da Educação Nacional - Lei Federal 9.394/96, de 20 de dezembro de 1996, Brasil.

${ }^{2}$ Como forma de respeito às questões de gênero e sexualidade, e por entender e defender que tais questões são b astante multiformes, procuramos utilizar neste trabalho uma escrita não-binária e anti-patriarcal em que o uso do X, no lugar da letra que empregaria o gênero, se faz presente muita das vezes em palavras que seriam escritas comumente de forma genérica, no masculino. Consideramos esta ação também como parte da perspectiva que criamos de Trans-form-AÇÃO, que seria transgredir, transformar, formar e agir, por um outro viés. Contra-hegemônico por assim dizer, seria também uma forma de resistência e insurgência, de luta e de reinvenção de novos caminhos, pois: "nuestra rebeldía es nuestro NO al sistema. Nuestra resistencia es nuestro SI a otra cosa posible" (EZLN, 2015, p. 221), aqui, a começar pela palavra escrita, que precisa ser RE-existida nos escritos acadêmicos. Sobre esta referência, ver em: (2015). El pensamiento crítico frente a la hifra capitalista I. Participación de la Comisión Sexta del EZLN. México: EZLN.
} 
Contrárixs a estas prerrogativas, nós, educadoras e educadores populares divergimos frontalmente deste tipo de prática verticalizada. Isto porque quando se transmite, não se troca; quando se repassa, não se constrói junto. E é aí que o conhecimento passa a ser não-participativo, portanto, não ativo, não criativo. Quando não se participa, não se tem a dimensão exata daquilo, daquela forma, do porquê daquele conhecimento, e não se consegue ainda relacioná-lo ao mundo cotidiano. Se não há o reconhecimento da validade daquele saber para a vida, não há identidade e identificação e a tendência é o afastamento, pelo não reconhecimento, por não ter a própria marca naquilo que deveria ser problematizado, relacionado, construído, desconstruído e REconstruído, conjuntamente.

Voltemos aos Círculos de Cultura da década de 1960 no Brasil em que se estimulavam o diálogo em suas rodas de conversa. Era através deles que se instaurava a problematização do cotidiano. Quando já havia um estado de "quebra-gelo", em que a vergonha de falar, o acanhamento havia dado lugar a dedos levantados e a corpos querendo se fazer ouvir por gestos, a problematização estava apta a surgir. Convidadas a examinar a realidade em que viviam, começavase assim a desnaturalização de opiniões acerca do mundo. Montero (2006, p. 231) vem nos dizer que "la problematização sensibiliza, desnaturaliza, establece las bases cognitivas y afectivas para producir una motivación de cambio que se traduce en acciones concretas de transformación"3. Como fruto destes trabalhos, ao menos duas publicações podemos registrar: o "Livro de Leitura para Adultos" e a cartilha "Viver é Lutar", do MCP e MEB respectivamente.

Como diz Fiori (in TORRES, 1981, p. 12) Paulo Freire fez da "pedagogia uma antropologia", e a nosso ver foi um grande etnógrafo, pois não havia método, como ele mesmo propagava, em suas ações de alfabetização no país. Mas tudo era feito de acordo com a realidade cultural e social de cada grupo, por meio de temas geradores e situações-limite, porque via para além de processos e burocracias. Assim como ele, xs demais entusiastas desta outra educação viam neste novo gestar pedagógico um papel central e revolucionário para transformação, do ser que está não só no mundo, mas com o mundo. Se num primeiro momento a apatia estava no centro da convivência naquele espaço, logo após as intervenções ela dava lugar a empatia, a confiança e podia-se enxergar e debater sobre as mazelas, a escassez, a falta, mas enxergava-se também o que abundava, os pontos positivos de suas realidades. Era, assim, a prática a responsável por trazer essas questões, problematizá-las e transformá-las não só no negativo, no "copo vazio", mas nas possibilidades que a própria escassez poderia trazer, e como trabalhar com elas e a partir delas,

\footnotetext{
${ }^{3}$ Tradução minha: "a problematização sensibiliza, desnaturaliza, estabelece as bases cognitivas e afetivas para produzir uma motivação de mudança que se traduz em ações concretas de transformação".
} 
tendo em vista sua transformação. Com estas propostas, partindo da subjetividade, do cotidiano, do que o participante trazia, era cada vez maior o número de grupos e ações que se formavam com estes moldes e práticas pedagógicas, inovadoras à época. "No contexto da sociedade brasileira, estas experiências foram sendo tecidas como uma criativa e original resposta político-pedagógica a uma concepção de educação dualista e disciplinadora, que servia de base ideológica a um modelo de sociedade profundamente desigual e conservadora, marcada pela força violenta do "mandonismo" e pela "cultura" da servidão e do medo" (ANDRADE, 2009, p. 04). Configuram-se assim estes espaços como território de resistências, como podemos chamá-los.

Entendemos aqui que não há motivo para a dissidência entre o educativo e o cotidiano (que ao nosso entender também é educativo), tampouco há razões para apartar o educativo do político (que ao nosso entender também é educativo). Entendemos que são nestas esferas que se forjam a criatividade, a autoconsciência, a emancipação, a afetividade, a pertença no seio da sociedade, mesclando subjetividade e objetividade para a real integralidade do ser humano, condições necessárias para o exercício pleno da verdadeira cidadania.

\section{O QUE DÁ LIGA AOS PROCESSOS PEDAGÓGICOS OUTROS}

Nos são inspiradoras para esta caminhada a articulação dos referenciais da Educação Popular com os da Decolonialidade, cruzando por meio dessas experiências pedagógicas as heranças da colonialidade nos 'territórios do $\mathrm{sul}^{4}$. A EP assim se insere na genealogia do pensamento crítico decolonial, enquanto prática e pesquisa social, ação e movimento, ligada a projetos de emancipação no fortalecimento de uma pedagogia decolonial em nosso continente. Isto posto, pensamos que a Decolonialidade e a EP por si se referem a "transgredir, deslocar e incidir na negação ontológica, epistêmica e cosmogônico-espiritual que foi - e é - estratégia, fim e resultado do poder da colonialidade" (WALSH, 2009, p. 27).

Dentro deste prisma, a avaliação seria um instrumento de grande valia, pois encontraria nas próprias situações do cotidiano de seus participantes a possibilidade de saída e de resolução de suas demandas. Contestando as matrizes pedagógicas, concatenando conteúdos à realidade e à realidade conteúdos pedagógicos, contextualizando, problematizando... Neste contexto, a Pedagogia da

\footnotetext{
${ }^{4}$ Entendemos por "territórios do sul", povos oprimidos de latinoamerica, do sul global, não deixando de fora, contudo, povos de África e Ásia, que também sofrem opressões dos povos "do norte". Emoutras palavras, o que se entende por sul, são povos fora da Europa e Estados Unidos que sofreram (e até hoje sofrem) as consequências das expansões capitalistas, que expropriou as riquezas materiais e aniquilou muitas das culturas dos povos do sul.
} 
Alternância $^{5}$ poderia estar assim inserida neste cenário, pois esta modalidade "assume que todo conhecimento é inseparável dos sujeitos e das experiências produtoras de conhecimentos, de valores, de cultura e de emancipação" (MORETTI, VERGÜTZ, CORRÊA, 2017, p. 832).

Assim que, o diálogo com outras formas de linguagens, de saberes, de aprendizagem, protagonizado que é por todxs que daquele momento fazem parte, retoma também duas questões importantes. A primeira delas é: qual a 'forma correta' de falar/abordar sobre uma dada questão? Por exemplo: rap, funk, música erudita, meio ambiente, jogos de celular, redes sociais e livros. A segunda, que acho que explica a primeira, é: não há escala hierárquica em nenhuma destas manifestações, nem saberes maiores ou menores, nem formas herméticas, fechadas e pré-moldadas de abordagem e linguagem, mas diferentes formas de se dar a conhecer e se descortinar uma questão que surge naturalmente no processo de diálogo. Além disso, questões que trazem de seu cotidiano e de suas realidades são problemas pedagógicos, sim. E por excelência.

Os currículos monoculturais do passado, voltados para si mesmos, etnocêntricos, desprezavam o "não formal" como "extra-escolar", ao passo que os currículos interculturais de hoje reconhecem a informalidade como uma característica fundamental da educação. O currículo "intertranscultural” (Padilha, 2004) engloba todas as ações e relações da escola; engloba o conhecimento científico, os saberes da humanidade, os saberes das comunidades, a experiência imediata das pessoas e considera a educação como um processo sempre dinâmico, interativo, complexo e criativo. (GADOTTI, 2012, p. 07)

Lendo o que Gadotti nos coloca, nos perguntamos se esses "currículos monoculturais do passado" realmente ficaram no passado ou se ainda fazem parte (ainda e infelizmente) do cotidiano de muitos espaços da educação formal. Será que o "currículo intertranscultural" de que nos fala se faz presente realmente nestes espaços? E, em conjunto com ele, as ferramentas de avaliação?

O conceito de Pensamento-outro, que aqui tomamos de empréstimo, vem de Abdelkebir Khatibi. O autor árabe-islâmico nos aponta um horizonte para pensarmos pelo viés da 'invisibilidade', da 'dominação', da 'desumanização', por exemplo. Dentro desta esfera, é por meio da decolonização que se parte por exemplo para as pelejas junto a movimentos sociais em prol de afirmação de existência, cultura e identidade, na busca e na luta por direitos. É assim que, como Walsh (2012), pensar a decolonialidade é pensar as lutas contra a colonialidade e, a partir dela, questioná-las e promover a reconstrução radical de toda a integralidade humana. Seria assim o

\footnotetext{
${ }^{5}$ Para o aprofundamento deste tema, ver mais em: http://www.scielo.br/scielo.php?script=sci arttext\&pid=S151797022008000200002.
} 
'pensamento crítico de fronteira' que nos coloca, para problematizarmos, questionarmos, perguntamos os porquês, estes que nos são tão negados nos processos pedagógicos formais de educação, por exemplo.

Repensar, portanto, as práticas pedagógicas e as políticas de avaliação da Educação de Jovens e Adultos, por exemplo, pode ser um importante passo e desafio para quem se preze a entrar por esta seara. E a Educação Popular pode ajudar muito nisto, justamente, porque "sabemos que essa possibilidade de uma nova forma de existência não é fruto do acaso, pois compreendemos que as experiências (alternativas e contra-hegemônicas) são indícios de que se tramam a esperança no homem e na mulher como sujeitos da transformação" (MORETTI, VERGÜTZ, CORRÊA, 2017, p. 829). É, portanto na certeza do inacabamento e das possibilidades emancipatórias de reassunção de sua própria história que reside a possibilidade de a Educação Popular atuar como mediadora neste processo.

Se formos fazer uma pesquisa, boca a boca que seja, com professorxs das mais variadas disciplinas e escolas, certamente quase que $100 \%$ deles e delas dirão que não são conservadorxs e nem atuam de forma conservadora em sala de aula. Apontarão ainda, de pronto, iniciativas de cunho "progressistas", com atividades isoladas, medianamente progressistas e minimamente democráticas. Mas se formos verificar, no cotidiano, suas ações e atuações em sala de aula e o modo com que se relacionam com suas turmas atestaremos o quanto de conservadorismo, de hierarquização existem em suas condutas. Isto porque há uma série de fatores para contribuírem com uma educação engessada, que por vezes não depende muito só da atuação dxs professorxs, mas que, em alguns casos, estxs são tão vítimas quanto xs alunxs tornando-se reféns deste tipo de 'prática educativa'.

Desta forma, mesmo que se tente agir de forma mais democrática e 'inovadora' em sala de aula, estx profissional acaba por encontrar barreiras que primam pela sua desqualificação e também perseguição, pela direção e por colegas que pensam de forma distinta e acabam por desvalorizar e satirizar suas ações quando estas tentam sair dos padrões normativos da escola regular e formal. Outro fator que promove e mantém a atividade educativa 'mais do mesmo' é quando com baixíssimos salários este profissional tem desse dividir entre inúmeras escolas, turmas e turnos, ficando desgastado e mesmo adoentado, acabando assim por optar por uma educação "feijão-comarroz’. Isto porque trabalhar com uma educação conservadora talvez seja muito mais fácil do que tratar a educação como crítica, esta que leva a pensar um projeto junto com cada turma, considerando suas especificidades. 
Se por um lado pode dar mais trabalho propor um projeto pedagógico voltado para as especificidades de cada turma, por outro, o resultado além de ser infinitamente mais proveitoso, torna-se mais prazeroso quando se faz junto, quando se avalia em conjunto. Temos visto em nosso cotidiano tantos profissionais adoentados, dependentes de remédios controlados, com licença médica por inúmeros transtornos psíquicos. Além da histórica exploração, desvalorização e sucateamento do profissional, que comentamos, essas patologias podem estar intimamente relacionadas ao ensino tradicional, de 'cima pra baixo', sem afeto, portanto, nas relações. Isto porque, em muitos casos quando x profissional se dá a entender a turma e suas peculiaridades e passa a construir junto, o diálogo e não a gritaria passam a fazer parte do cotidiano das relações, por exemplo. A calmaria toma conta por meio do respeito mútuo e autogestionado, justamente porque passa a fazer sentido aquela relação, e tudo o que ela constrói e dela resulta.

Sobre esta mesma esfera de pensamento, Vera Candau (2011), em seus estudos sobre o cotidiano escolar, coloca que: "A cultura escolar dominante em nossas instituições educativas, construída fundamentalmente a partir da matriz político-social e epistemológica da modernidade, prioriza o comum, o uniforme, o homogêneo, considerados como elementos constitutivos do universal" (p. 241). Assim, dentro do que nos propomos neste trabalho, nosso objetivo também é contrapor ao modelo de civilização escolar urbanocêntrico (RIBEIRO, 2008), que não vê na escola rural, indígena e quilombola, por exemplo, possibilidades de. É a teoria evolutiva de ser humano que tanto se via na antropologia dos séculos passados, ainda presente nas cadeiras escolares, em que apenas um modelo é possível, enquanto aquele que não está dentro dessa 'esfera pensante', chegará, quem sabe um dia, ao mesmo 'patamar de evolução'. Vemos isso de forma corrente nas escolas regulares também na urbe, sobretudo aquelas incrustadas ou localizadas no interior de favelas e periferias, principalmente nas suas turmas de Educação de Jovens e Adultos.

Contrapondo-se a isto, fazer parte destes processos educativos nos faz visualizar práticas sociais que acenam para situações que nos requerem problematização, desnaturalização e complexidade, porque partem da ação e do movimento: das realidades que ali se expressam, do cotidiano, das subjetividades. E é isto que nos faz compreender dialeticamente o nosso papel naquele espaço e ao mesmo tempo na nossa vida secular (MINAYO, 2000). É dentro deste processo que comungamos com Paulo Freire quando afirmava que: "deste modo, fazendo pesquisa, educo e estou me educando com os grupos populares" (1999, p. 35-36). Descobrindo-nos juntxs, rindo juntxs, chorando juntxs. Aprendendo juntxs. 


\section{A EDUCAÇÃo POPULAR COMO SAÍdA POSSÍVEL}

Dentro do que se propõe, a Educação Popular busca provocar a instrumentação de um saber pautado por uma educação radical que acompanhe o processo de feridas históricas e o relacione às feridas locais (eu e minha trajetória), que se apresentam no interior do cotidiano das relações (eu e meus pares), de forma a problematizá-las e a confrontá-las. E isto se dá por meio da construção de espaços de reflexão crítica, que contribuam para o desenvolvimento de uma consciência sobre a prática, a realidade, o cotidiano, buscando o fortalecimento da luta social em prol de mudanças. Por sua vez, aprender com o passado (quem eu fui), para entender o presente (quem eu sou) e buscar saídas e estratégias para o futuro (quem eu serei) pode ser à primeira vista algo bem ingênuo e abstrato, mas torna-se, entretanto, imprescindível para que desnaturalizemos os processos de opressões conjunturais que a cada dia somos sujeitados. Serve em igual medida para que nos entendamos enquanto sujeitos, conhecendo nossa ancestralidade, nossas reminiscências para que os nossos processos atuais e futuros tenham uma compreensão crítica e não passem despercebidos pela falta de sensibilidade por nós mesmos.

Foi o ideal positivista que deu sustentação ao modelo de educação que entendemos hoje, justificando uma ordem capitalista velada que legitimou por meio de uma suposta razão a dominação de classe. Hoje se constrói um discurso semelhante com novas roupagens neoliberais para justificar formas antigas de dominação e perpetuação de poder. Para tanto, Emancipar-se, augestionar-se está para além de uma ação prática propriamente dita, é uma ação política que se desenvolve numa amplitude cosmológica e tem sua plenitude a partir do $e u$, questão afetivoemocional, partindo para a ação política e social, 'eu no mundo e com o mundo', trazendo para si a responsabilidade de que nos falava Freire (1987). Criticando o poder das ideologias justapostas, em que o "sempre foi assim" se faz presente todo o tempo procurando legitimar diferentes situações de opressão, que mascaram realidades e se revelam como saída única para se viver em sociedade. Para tanto, estabelecer ações educativas que cumpram um papel desafiador e provocador, dentro e fora dos espaços escolares, numa formação consoante com experiências e realidades é o primeiro passo para que essas críticas e desafios se tornem ações efetivas que, de fato, libertem.

Em conformidade com o que pontuamos, Nunes (1999) afirma que,

A educação popular não pode aceitar a lógica do mundo globalizado [...] tem que continuar como um núcleo sadio de resistência política, de ampliação da participação cultural, coletiva, de recuperação da fala autêntica, relações de respeito, familiaridade e diálogo. [...] promover a decisão coletiva sem clientelismo e assistencialismo. Responsabilidade no que decide, solidariedade orgânica e afetiva, fraternidade, 
consciência crítica, palavra autêntica e coração solidário [...] são estas categorias que a E. P. precisa para que o núcleo popular venha a ser um dia o modelo hegemônico. (p. 7-8).

Para Paulo Freire, educação e antropologia caminham juntas, pois que, é entendendo a cultura dx participante e dos diferentes contextos de vida do grupo que assim muitos processos históricos embutidos são revelados como construções de um ideal de sociedade estruturalmente delimitado. É a partir daí que se desenvolvem ações de forma a assumir definitivamente suas culturas como redes de significantes e significados importantes e mesmo imprescindíveis para estes processos de desconstrução. O próprio projeto de uma outra educação, em nosso caso a EP, já faz uma denúncia prévia da falta de oportunidades, da disparidade e das desigualdades descomunais nas trajetórias sociais, individuais e coletivas dos grupos que compõem suas ações.

No tocante às políticas públicas para e com a Educação de Jovens e Adultos, em consonância com a Educação Popular, que as entendemos aqui pela via dos direitos. Assim, uma política pública bem ajustada é aquela que dê subsídio aos municípios para sua atuação, bem como, que atue na responsabilização de seu cumprimento através da fiscalização e avaliação, por meio da própria população, que consultada desde sua formulação poderá ser o termômetro para sua eficácia e efetiva implementação. É por meio da criação de espaços de diálogo e negociação que tais políticas poderão se tornar de fato participativas e eficazes em seus propósitos. Assim, "Não se trata de duvidar das intenções. O que está em questão é o próprio caráter político-pedagógico do processo, desde sua concepção, passando pelo planejamento, pela implementação, execução, acompanhamento, avaliação, etc.” (CALADO, 2008, p. 03).

Nas palavras de Fals Borda, "Participación es, por lo tanto, el rompimiento de la relación tradicional de dependencia, explotación, opresión o sumisión a todo nivel, individual y colectivamente: de sujeto/objeto a una relación simétrica o de equivalencia"6 (1987, p. 04). É também nesta seara que a autocrítica se faz presente enquanto projeto permanente de atualização da prática docente no intuito de que nos percebamos como seres incompletos e, nessa incompletude, nos debrucemos a outras formas e grupos que pensam e olham o mundo de maneiras diversas, de forma a pluralizarmos nosso olhar.

\footnotetext{
${ }^{6}$ Tradução minha: Participação é, portanto, o rompimento da relação tradicional de dependência, exploração, opressão ou submissão a todo nível, individual e coletivamente: de sujeito/objeto para uma relação simétrica ou de equivalência.
} 
A hegemonia das técnicas e métodos de pesquisa e práticas educativas tradicionais são largamente desafiados nos espaços de construção de saberes outros. A "subversão moral" de que nos coloca Fals Borda (1971) é o pressuposto que traduz sistematicamente o que é emergir da condição de oprimido à portador de fala e história, desafiando os cânones da ciência e da política e seus métodos hegemônicos e parciais.

É dentro de uma aposta de superação e transposição à colonialidade nas pedagogias, que a Educação Popular se configura como um processo aberto e contínuo, não involuntário, tampouco finito e com apenas uma frente de atuação. Diferente disto a EP se contrapõe de maneira frontal aos processos de educação que tradicionalmente serviram para a formação de uma não-cidadania, num contexto de subalternização das classes, elegendo uns em detrimento de outrxs. Escolhendo quem serviria e quem seria servido à mesa.

Para além de um formato dual e adestrador, não seria de forma alguma "dirigir as massas", mas conduzir e mediar o processo de criar, recriar e problematizar conhecimentos. A dialogicidade se faz presente de forma radical neste tipo de relação. Em consonância com a perspectiva decolonial, a EP prevê a saída dos espaços periféricos de uma epistemologia subalternizada rumo à uma epistemologia onde a participação do outro se transporte destes espaços periféricos para o centro dos processos educativos, porque coletivos e coletivizados e ainda para a construção e execução de políticas públicas e instrumentos de avaliação de fato congruentes e carregados de sentido, porque participativos. Ter lentes que aproximem sua luta à de outros e outras, xs faz perceber que não se está sozinho e o sujeito individual só o é, por que tem no coletivo sua chave para existência. Sendo assim, o devir: o vir-a-ser se constrói antes da luta, quando se descobre enquanto colonizado e esta descoberta só se dá na práxis cotidiana de pensamentoreflexão-ação. E é justamente no "reconhecimento do seu pouco saber de si que se formará uma das razões desta procura" (FREIRE, 2005, p. 29).

Vemos que a disputa por narrativas é uma constante nestes espaços. Ousar e bancar uma conduta outra não é fácil. É enfrentamento. Concordamos ainda com Freire (1999) quando diz: “o grande problema que se coloca ao educador ou à educadora de opção democrática é como trabalhar no sentido de fazer possível que a necessidade do limite seja assumida eticamente pela liberdade" (p. 118). Isto porque, para fazer alguma coisa junto com outras pessoas é necessário admitir que não se "é suficiente" sozinho; que, não se bastando, é preciso ampliar suas potencialidades somando capacidades, pensamentos, forças, intenções. Fazer juntos pressupõe autogestão. É reconhecer os próprios potenciais e limites e os do outro, o que implica na convivência respeitosa com as 
diferenças. É por meio do diálogo que este fazer juntos acontece, pois é por meio dele que nos constituímos nestes espaços e adquirimos identidade no grupo. Assim, a relação dialógica é a condição primeira para a realização de uma ação conjunta entre x 'educadorx popular decolonial', que assim categorizamos, e x participante. A empatia e afetividade, neste caso, são de extrema importância para o desenvolvimento de um trabalho verdadeiramente transformador.

\section{ENTRE DIÁLOGOS E RE-EXISTÊNCIAS}

"Porque é melhor saber para onde ir, e não saber como, do que saber como e não saber para onde $i r$ "'. É que tendo a direção, o rumo e o lugar, fica mais fácil neste processo fazer o "como". Deste modo, ter a consciência de que o primeiro desafio ax educadorx popular decolonial é com elx mesmx, pensando práticas para que não se perca a autocrítica, tampouco se deixe entrar o ego apostólico que insiste em bater à porta nas atividades do cotidiano. É esta a direção que não se constrói para, mas com.

Entender que cada sujeito é único neste processo e ao mesmo tempo, coletivo, é primordial para o que se objetiva nas ações pedagógicas, sejam elas realizadas em espaços formais e nãoformais de educação. Desta feita, o envolvimento de cada um depende em grande medida dos esforços empreendidos pelx 'educadorx popular decolonial', na adequação de suas propostas visando a aproximação de cada participante com o grupo, bem de suas demandas e realidades próprias. Assim que, levar em conta a oralidade dx participante e suas narrativas, talvez mais que a escrita é perceber que a dialogicidade precisa estar em consonância o tempo todo no interior daquele espaço. Deste modo, a motivação e a atenção sendo facilitadas por meio do diálogo abarcarão um conjunto de aspectos cognitivos que fruirão naturalmente nestes espaços de construção de conhecimentos outros.

Afirmar a educação como um processo de resistência, enfrentamento e, por fim, um projeto omnilateral de ser e estar no mundo seria um indicativo necessário para este tipo de proposta. Símon Rodriguez, por exemplo, pensava a Educação Popular como um "sistema de socialização para o desenvolvimento das capacidades de ações coordenadas no plano social, com vistas ao exercício do poder, tendo o diálogo como ferramenta" (STRECK; MORETTI, 2013, p. 36). Daí a necessidade de se ampliar o nível de compreensão crítica, bem como sua capacidade de indignação. Entendendo que situações-limite só são modificadas e transformadas com ações-limite, capaz de enfrentamentos lúcidos, concretos e basais. É assim uma "tensión entre teoría y práctica que

\footnotetext{
${ }^{7}$ (Personagem José Dolores no filme Queimada, 1969)
} 
conduce a un diálogo entre saberes teóricos y saberes prácticos convirtiendo al investigador en un educador desde el principio freiriano de la "concientización dialógica"8 (ORTIZ e BORJAS, 2008, p. 618).

A cada trabalho lido, a cada chão pisado numa escola, a cada abertura para a fala de seus alunos e alunas, constata-se a necessidade de espaços formais que se distanciem do senso comum, que concatenem o saber historicamente sistematizado, com o saber que verse sobre os seus conceitos trazidos da educação informal, da rua, de seus pares. É assim que esta ponte entre a escola e a sociedade precisa se ajustar, de modo que não se reduza tudo somente ao científico, mas que se construa pilares de diálogos, alicerçados no conhecimento de ambos: ciência/vivência-experiência.

A visão da liberdade tem nesta pedagogia uma posição de relevo. É a matriz que atribui sentido a uma pratica educativa que só pode alcançar efetividade e eficácia na medida da participação livre e crítica dos sujeitos envolvidos neste processo. É um dos princípios essenciais para a estruturação do círculo de cultura, unidade de ensino que substitui a "escola", autoritária por estrutura e tradição. Busca-se no círculo de cultura, peça fundamental no movimento de educação popular, reunindo o povo na conquista da linguagem e o diálogo é condição essencial com a tarefa de coordenar, jamais influir ou impor respeitando a liberdade dos aprendizes. (FREIRE, 1967, p. 4).

Somos testemunhas de que a educação tradicional que se faz no ensino regular das escolas por vezes não aglomera e aglutina debates que permeiam a vida social e cotidiana de seus indivíduos, buscando promover diálogos e entrelaçamentos. Tampouco busca formas de consolidar vínculos. Talvez porque seja essa mesma a questão: não formar vínculos de afeto e identidade neste tipo de educação. Diferentemente da EP que, com sua afetividade e com suas estratégias de resistências desafiadoras ao status quo que domina e oprime, pode, possivelmente, tornar visível e legitimar os 'excluídos desta terra' ao desnaturalizar opressões minimamente veladas em seu cotidiano. Exatamente porque sua missão é desvelar tudo o que se passa "como se o padrão de vida e de direitos das classes médias fossem extensíveis, sem mediações, para as classes populares, quando na verdade esses padrões resultam de formas históricas de utilização privilegiada de meios e recursos" (VALLA, 2009, p. 11). São desses privilégios que precisamos falar e criticizar. É da meritocracia, que historicamente legitima a interdição de trajetórias, que precisamos problematizar em nossos espaços de atuação, quaisquer que sejam eles.

\footnotetext{
${ }^{8}$ Tradução minha: tensão entre teoria e prática que conduz a um diálogo entre saberes teóricos e saberes práticos convertendo o investigador em um educador desde o princípio freireano da "conscientização dialógica".
} 
São nesses diálogos interculturais (que surgem numa aula de geografia, por exemplo) que a autoestima floresce, pois se reconhece o valor individual e subjetivo, coletivo e comunitário, ao mesmo tempo. Cultural. É, sobretudo, a dimensão de classe que se revela nestes diálogos. E raça. E gênero. E sexualidade. E cultura.

Evidente que nem todos os espaços formais de educação são hermeticamente fechados e iguais. Há sim os mais progressistas, que se diferenciam dos mais tradicionais, mas o que ocorre em sua maioria, principalmente no contexto das escolas públicas, por exemplo, é a padronização do ensino, o uso restrito de laboratórios e bibliotecas, estes, quase intocáveis. Encerrados em suas 'caixinhas', estes espaços perdem todo o 'recheio do bolo', que é a grande diversidade que permeia os espaços escolares em sua formalidade.

Emancipação seria assim a palavra que gesta, em nosso entender a Educação Popular e seus vários braços de atuação, cujas demandas e prerrogativas acabam por se distanciar, as vezes de forma natural, dos espaços formais de educação, onde ela não encontra voz e vez para atuar. O que não quer dizer, contudo que não haja práticas de EP acontecendo na escola regular e em demais espaços formais de educação. Como observado anteriormente, há muitos companheiros e companheiras que lutam por isto em seus espaços de atuação, mas sabemos que são rechaçados, desqualificados e perseguidos muita das vezes ao tentarem inserir formas de Educação Popular em suas turmas e nas próprias ações conjuntas de suas escolas. Sabemos ainda que trabalhar com a EP pode dar mais trabalho do que a forma tradicional de lecionar conhecida como 'cuspe e giz' (o 'feijão-com-arroz' que acima mencionamos). Isto porque, a respeito do que se espera enquanto início, meio e fim, cada uma destas formas de educação, tanto a tradicional-conservadora, quanto a EP, são vias pedagógicas que, definitivamente, não se cruzam.

São as pedagogias críticas que estão na base destas práticas, que se retroalimentam, pois têm o mesmo fim a perseguir: "são educações que concebem o estado e a sociedade como uma arena (no sentido Gramsciano) dentro dos quais é preciso marcar posição, garantir conquistas e conquistar novos direitos, trabalhando com as contradições e limites existentes tanto no estado quanto fora dele" (GADOTTI, 2012, p. 02). A Educação Popular aí estaria ancorada num trabalho pedagógico para além do espaço da sala de aula e da escola, o que não quer dizer que ela não possa estar presente nestes espaços. Muito ao contrário, a EP deve ocupar o maior número de locais onde a aprendizagem esteja presente, toando uma outra canção, mais horizontal e equalizada. Para tanto, a Educação Popular trabalhada em conjunto com outras formas de educação em vários espaços pode trazer frutos prósperos, impedindo a perpetuação de padrões racistas, classistas, machistas e homofóbicos, por meio de ideias truncadas, errôneas e injustas, tendo já de início a 
instrumentalização da avaliação como uma importante ferramenta, que trabalhada com honestidade em sua elaboração e execução certamente nos conduzirá para caminhos pedagógicos mais democráticos e de RE-existência.

Por fim, revisar nossa prática e exercer a autocrítica nos faz sairmos dos pilares de canonização própria que insistem em nos cooptar. É o exercício de revisão e autoavaliação permanente, mas sobretudo de abrir-se a novos rumos e mudanças, pois como educadorxs e militantes, precisamos, assim como Fals Borda: "se puede afirmar que Fals Borda practicó con rigurosidad la apertura al cambio permanente, era un intelectual tranformador cuya práctica le exigía abrirse a nuevas teorías, así como a una actualización permanente y consecuente del ejercicio político del cambio social y la democracia" (CALDERÓN e CARDONA, s/d, p. 04). É desta autocrítica, que tanto já insistimos aqui, que precisamos nos revestir. E, somado a isto, nos abrir a mudanças é salutar para que a nossa prática não se engesse de certezas. Isto, pode ser, quem sabe, o item número um e o primeiro passo para um instrumento de avaliação outro.

\section{REFERÊNCIAS}

ANDRADE, Edinaldo Costa de. A Educação Popular versus a "educação do popular": diferentes horizontes da emancipação humana no contexto atual. [S.l.: s.n.], 2009. Disponível em: <http://www.uff.br/iacr/ArtigosPDF/ 55T.pdf>.

CALADO, Alder Júlio F. Movimentos Sociais Populares rumo a uma nova Sociedade: do consenso ideológico ao dissenso alternativo. In: GONÇALVES, Moisés A.; CONCEIÇÃO, Geraldo Magela. (Orgs.). Outros Olhares Debates contemporâneos. Belo Horizonte: Leiditathi, 2008. p. 13-60.

CANDAU, V.M.F. Diferenças culturais, cotidiano escolar e práticas pedagógicas. Currículo sem Fronteiras, 11(2), 240-255. Recuperado de: 〈http://www.curriculosemfronteiras.org/voll1is s 2artic les/candau.pdf〉.

FALS BORDA, Orlando. Aspectos teóricos da pesquisa participante: considerações sobre o significado e o papel da ciência na participação popular. In: BRANDÃO, Carlos Rodrigues. (Org.). Pesquisa participante. 2. ed. São Paulo: Brasiliense, 1987. p. 34- 41.

Aspectos teóricos da pesquisa participante: considerações sobre o significado e o papel da ciência na participação popular. In: BRANDÃO, Carlos Rodrigues (Org.). Pesquisa participante. 2. ed. São Paulo: Brasiliense, 1971. p. 34- 41.

Da pedagogia do oprimido à pesquisa participativa. In: STRECK, Danilo. (Org.). Fontes da Pedagogia Latino-Americana: uma antologia. Belo Horizonte: Autêntica Editora, 2008.

Pesquisa-Ação, ciência e educação popular nos anos 90. In: STRECK, Danilo. (Org.). Fontes da Pedagogia Latino-Americana: uma antologia. Belo Horizonte: Autêntica Editora, 1994.

La investigación-acción participativa: política y epistemología. In: GUERRA, José María Rojas. (Org.). Antología Orlando Fals Borda. Bogotá: Universidad Nacional de Colombia, 2010 [1986].

; RODRÍGUEZ BRANDAO C. Investigación Participativa. Montevideo: La Banda Oriental, 1987.

\footnotetext{
${ }^{9}$ Tradução minha: se pode afirmar que Fals Borda praticou com rigorosidade a abertura a mudanças permanentes, ele era um intelectual transformador, cuja prática lhe exigia abrir-se a novas teorias, assim como a uma atualização permanente e consequente do exercício político da mudança social e da democracia.
} 
FALS BORDA, Orlando; RAHMAN, A. "La situación actual y las perspectivas de la IAP en el mundo" [S.l.: s.n.],1989. In: SALAZAR, M. La investigación-acción participativa. Inicios y desarrollo. Consejo de Educación de Adultos de América Latina, Universidad Nacional de Colombia. OEI, Quinto Centenario. Madrid: Editorial Popular, 1992.

FANON, Frantz. Los Condenados de la Tierra. Buenos Aires: Fondo de Cultura Económica, 1979.

FÁ VERO, O. (Org.). Cultura popular, educação popular: memória dos anos 60. Rio de Janeiro: Graal, 1983.

FREIRE. P. Educação como prática da liberdade. Edições variadas. Rio de Janeiro: Paz e Terra, 1967, 1976, 1983, 1999, 2003.

Educação e mudança. 30. ed., Rio de Janeiro: Paz e Terra, 2007.

Pedagogia da autonomia: saberes necessários à prática educativa. Edições variadas. São Paulo: Paz e Terra, 1996, 1997, 2002, 2015.

Pedagogia da tolerância. São Paulo: UNESP, 2004.

Pedagogia do oprimido. Edições variadas. Rio de Janeiro: Paz e Terra, 1970, 1987, 2005.

À sombra desta mangueira. São Paulo: Olho D’água, 2010.

; NOGUEIRA, Adriano. Que fazer: teoria e prática em educação popular. Rio de Janeiro: Vozes, 1989.

GADOTTI, Moacir. Educação Popular, Educação Social, Educação Comunitária: conceitos e práticas diversas, cimentadas por uma causa comum, p. 10-32. Revista Diálogos: pesquisa em extensão universitária, Brasília, v. 18, n. 1, dez. 2012.

MINAYO, Maria Cecília S. O desafio do conhecimento: pesquisa qualitativa em saúde. 7. ed. São Paulo: HUCITEC; Rio de Janeiro: ABRASCO, 2000.

MONTERO, M. Hacer para transformar: el método en la psicología comunitaria. Buenos Aires: Paidós, 2006.

MORETTI, C.Z.; CORRÊA, Aline M.; VERGUTZ, C.L.B. Possibilidades Emancipatórias na Escola Família Agrícola de Santa Cruz do Sul: Diálogos entre a Pedagogia da Alternância e a Educação Popular. Revista E-Curriculum, PUCSP, v. 15, p. 821-841, 2017.

MORETTI, C. Z.; STRECK, D. R. Colonialidade e insurgência: contribuições para uma pedagogia latino-americana. In: Revista Lusófona de Educação, v. 24, p. 33-48, 2013.

ORTIZ, Marielsa; BORJAS, Beatriz. La Investigación Acción Participativa: aporte de Fals Borda a la educación popular. In: Espacio Abierto, Universidad del Zulia Maracaibo, Venezuela, vol. 17, n. 4, p. 615-627, oct.-dic. 2008.

NUNES, César. Educar para a Emancipação. Florianópolis: Sophos, 2003.

RIBEIRO, M.. Educação Popular: um projeto coletivo dos Movimentos Sociais Populares. Perspectiva, UFSC, v. 26, p. 41-68, 2008.

TORRES NOVOA, Carlos Alberto. Leitura Crítica de Paulo Freire. São Paulo: Loyola, 1981.

VALLA, Victor Vincent. Problematizando o termo "conversão", a partir do campo religioso. In: VALLA, Victor Vicent et al. (Org.). A contribuição de Victor Valla ao pensamento da Educação Popular: diferentes olhares. Rio de Janeiro, 2009.

WALSH, Catherine. Interculturalidad y (de)colonialidad: perspectivas críticas y politicas. Visão Global, Joaçaba, SC, v. 15, n. 1-2, p. 61-74, jan./dez. 2012.

Interculturalidade, crítica e pedagogia decolonial: in-surgir, re-existir e reviver. In: CANDAU, Vera Maria. (Org.). Educação intercultural na América Latina: entre concepções, tensões e propostas. Rio de Janeiro: 7Letras, 2009. 


\section{RESUMO}

O presente artigo pretende tecer um diálogo com a Educação Popular como uma forma outra de fazer educação e instrumentalizar os processos de avaliação e políticas públicas. Não se trata somente de um discurso sob uma outra ótica, mas o compromisso ético-político de pensamento e prática que difiram e desconstruam conhecimentos coloniais, abrindo caminhos para epistemes de resistência ou: RE-existência. A EP se não pode ser a saída, ela pode ao menos apontar e trazer muitas possibilidades de um pensamento decolonial que vá de encontro a pedagogias hegemônicas e dominantes. O que se trata é de criar novos espaços de epistemologias-outras, bem como ocupar antigos locais que servem ainda a uma epistemologia universalizada e estruturalmente enraizada em processos históricos de dominação, que tem raça, gênero e localização geográfica bem definidos.

Palavras-chave: Avaliação. Educação Popular. Re-Existência.

\section{RE-EXISTENCE BEGINS IN DIALOGUE - ON POPULAR EDUCATION AND OTHER FORMS OF EVALUATION}

\section{RESUMEN}

El presente artículo pretende hacer un diálogo con la Educación Popular como una forma otra de hacer educación e instrumentalizar los procesos de evaluación y políticas públicas. No se trata sólo de un discurso bajo otra óptica, sino el compromiso ético-político de pensamiento y práctica que difieren y deconstruyen conocimientos coloniales, abriendo caminos para epistemés de resistencia o: RE-existencia. La EP si no puede ser la salida, ella puede al menos apuntar y traer muchas posibilidades de un pensamiento decolonial que vaya contra pedagogías hegemónicas y dominantes. Lo que se trata es de crear nuevos espacios de epistemologías-otras, así como ocupar antiguos lugares que sirven aún a una epistemología universalizada y estructuralmente enraizada en procesos históricos de dominación, que tienen raza, género y localización geográfica bien definidos.

Palabras clave: Evaluación. Educación Popular. Re-Existência.

\section{LA RE-EXISTENCIA COMIENZA EN EL DIÁLOGO - SOBRE EDUCACIÓN POPULAR Y FORMAS OTRAS DE EVALUACIÓN}

\section{ABSTRACT}

This article intends to create a dialogue with Popular Education as a way of educating and instrumentalizing evaluation processes and public policies. It is not only a discourse from another perspective, but the ethicopolitical commitment of thought and practice that differs and deconstructs colonial knowledge, opening the way to epistemes of resistance or: RE-existence. The EP can not be the exit, it can at least point and bring many possibilities of a decolonial thought that goes against hegemonic and dominant pedagogies. What is involved is to create new spaces of epistemologies-other, as well as to occupy old places that still serve a universalized epistemology and structurally rooted in historical processes of domination, that have race, gender and geographical location well defined.

Keywords: Evaluation. Popular Education. Re-Existence.

Submetido em: 17 de julho de 2018

Aprovado em: 30 de abril de 2019 